\title{
ERP SYSTEMS AND INTERNAL AUDIT
}

\author{
Aditya Saharia, Fordham University, saharia@fordham.edu \\ Bruce Koch, Seattle University, kochb@seattleu.edu \\ Robert Tucker, University of Florida, robert.tucker@cba.ufl.edu
}

\begin{abstract}
From an internal audit perspective, enterprise systems have created new opportunities and challenges in managing internal as well as external risks. In this work, we report results of a survey that examines internal auditors' ability to identify and manage operational, financial, technological, compliance and other risks as the organization migrates to an ERP environment. Our findings show that the internal auditors perceive a reduction in financial and operational risk and an increase in technical risks. These effects are somewhat mitigated by their ability to assess and manage these risks. We also find that internal audit departments satisfied their needs for ERP skills not by outsourcing but by providing staff with in-house training.
\end{abstract}

Keywords: ERP, Internal Audit, Risk Management, System Implementation

\section{INTRODUCTION}

Enterprise resources planning (ERP) systems arrived on the accounting scene with much fanfare in 1990s. These systems, which are essentially vendor defined enterprise wide accounting systems, promised fully integrated applications built upon common, centrally defined databases. The benefits of these systems were supposed to be manifold. An ERP system would eliminate the need to manage information flows manually by allowing the effect of every business transaction to be disseminated throughout the enterprise via update to a common database. It would provide real-time information to support operational and managerial decision activities as every application would be working with the current version of the operational database rather than working with slightly stale data as was the case in old fragmented systems. An adopting organization would be able to reduce the time to close accounts and create financial reports in real time, as the data in databases is current all the time. As an ERP system incorporates country specific accounting standards, allow for currency transaction and local labor laws, a multinational firm can use a common system to support its operation in different countries. Finally, the potential nightmare of $\mathrm{Y} 2 \mathrm{~K}$ bug provided an additional impetus for adoption [3, 10].

Yet the adoption and acceptance of ERP systems has been less than ideal. These systems are complex and touch upon many business processes that cut across functional boundaries. Before redefining the organizational structure, the set of accounts, and business processes; specifying new master and transaction data items; and choosing among accounting methods, it becomes necessary to meticulously re-examine organization structure and business processes. As part of implementation, many steps embedded in the old environment become unnecessary, particularly those associated with managing the flow of data and information across organization boundaries or managing workflow documents. This in turn leads the adopting firm to reengineer itself both at the entity and process levels. The ERP implementation projects thus face very significant technical and organizational challenges. Despite following a structured project management methodology, these projects often fail or never realize their full promise. Many cases exist of cost overruns, missed completion deadlines, abandoned implementations, and, in a very few cases, bankruptcies associated with attempted ERP implementations. Many organizations found that even after implementing ERP systems, managers were depending on manual procedures and reports created by the old legacy systems $[6,8,11,12]$.

From an internal audit perspective, ERP systems created new opportunities as well as new challenges $[2,4]$. On one hand, the use of an integrated system increases transparency in business processes and, at the same time, eliminates the need for controls assuring data consistency and accuracy as data move from one system to the next. With a single data entry point, need for entering the data associated with a transaction separately into different applications is eliminated; and therefore the controls to enforce data validity, data accuracy, and data privacy constraints 
need to implemented only once. As the system resides in one centrally controlled database, the risk of privacy violation can be identified more easily and the steps necessary to satisfy privacy constraints can be implemented more readily. Integrated systems provide for improved audit planning and execution. If a new government regulation requires the organization to institute a new internal control, is has to be incorporated only once into an integrated system [9].

On the other hand, the complexity of an ERP system creates additional risks during both the implementation and the operational stages. During the implementation, the organization faces risks due to possible poor project planning and control, dependence on external consultants and integrators, resistance to organizational change, and lack of specialized skills needed to customize the system and populate it with organizational data [5, 11, 12]. Even when implementation is relatively smooth, risks remain during the operational phase. An integrated environment often precludes the possibility of switching to a new system for an individual function, even if the new system has better functionality and easier maintenance routines. An integrated system presents the possibility that a small glitch introduced in one part of the system, perhaps as part of a routine maintenance activity, brings down the entire system potentially disrupting the firm's business operations. In essence, the benefits of a unified integrated system are traded off against the risk diversification achieved with multiple, independent systems. Integrated systems also complicate audit planning as the auditor must gather evidence encompassing the entire system in an integrated manner [1, 7]

While there have been many studies of the risks in ERP implementations, there is not much research on the role that internal auditors play in ERP adoption and the impact ERP systems have on internal auditors' abilities to manage risks. In this work, we address this gap. We surveyed a group of internal auditors to explore the effects of ERP systems on internal audit functions. In particular, we wanted to identify how ERP systems affect risks faced by an organization and how ERP systems affect internal auditors' ability to identify and manage these risks. Our survey asked the respondent to identify (i) background information (characteristics or the organizations, systems implemented, and role of internal auditors in the implementation process); (ii) changes in level of risks (using qualitative scales like increase, decrease or no change), ability to identify risks, and ability to manage risks in four different categories (operational, financial, technical, and other risks); (iii) changes in costs associates with risk identification; and (iv) the mechanism followed to acquire special skills needed to carry on internal audit functions in an ERP environment.

We sent hard copies of the survey to the members of the New York Chapter of the Institute of Internal Auditors. We received nine responses from internal auditors at member organizations that had adopted ERP systems in some part of the organization. Subsequently, we posted an online version of the survey on the Institute of Internal Auditor's online survey site http://www.theiia.org/guidance/ benchmarking/flash-surveys/. We received an additional 38 responses. Our findings below are bases on responses both sources.

For sake of brevity, we have not provided charts and graph for every category but only the ones that describe the main effects. More detailed survey results as well as the survey instrument are available from the authors.

\section{INTERNAL AUDITORS' ROLE DURING ERP IMPLEMENTATION}

Despite the significant organizational risk associated with change management that often results from an ERP implementation, involvement of the internal auditors in ERP implementation was not as heavy as we had expected; only in one third of the cases, internal auditors were proactively involved in change management. Despite their lack of involvement in the implementation process, majority of respondents felt that their firms followed structured processes for change management associated with the ERP implementation.

We were surprised to find that internal auditors were not as actively involved in defining and implementing internal controls as new modules implemented and existing modules are enhanced or maintained. Only a quarter of respondent were heavily involved in building internal controls and only one-fifth of the respondents were involved in business process reengineering efforts. These issues perhaps reflect a broad perception that ERP implementation are often led and managed by information systems groups and not treated as enterprise wide efforts. 


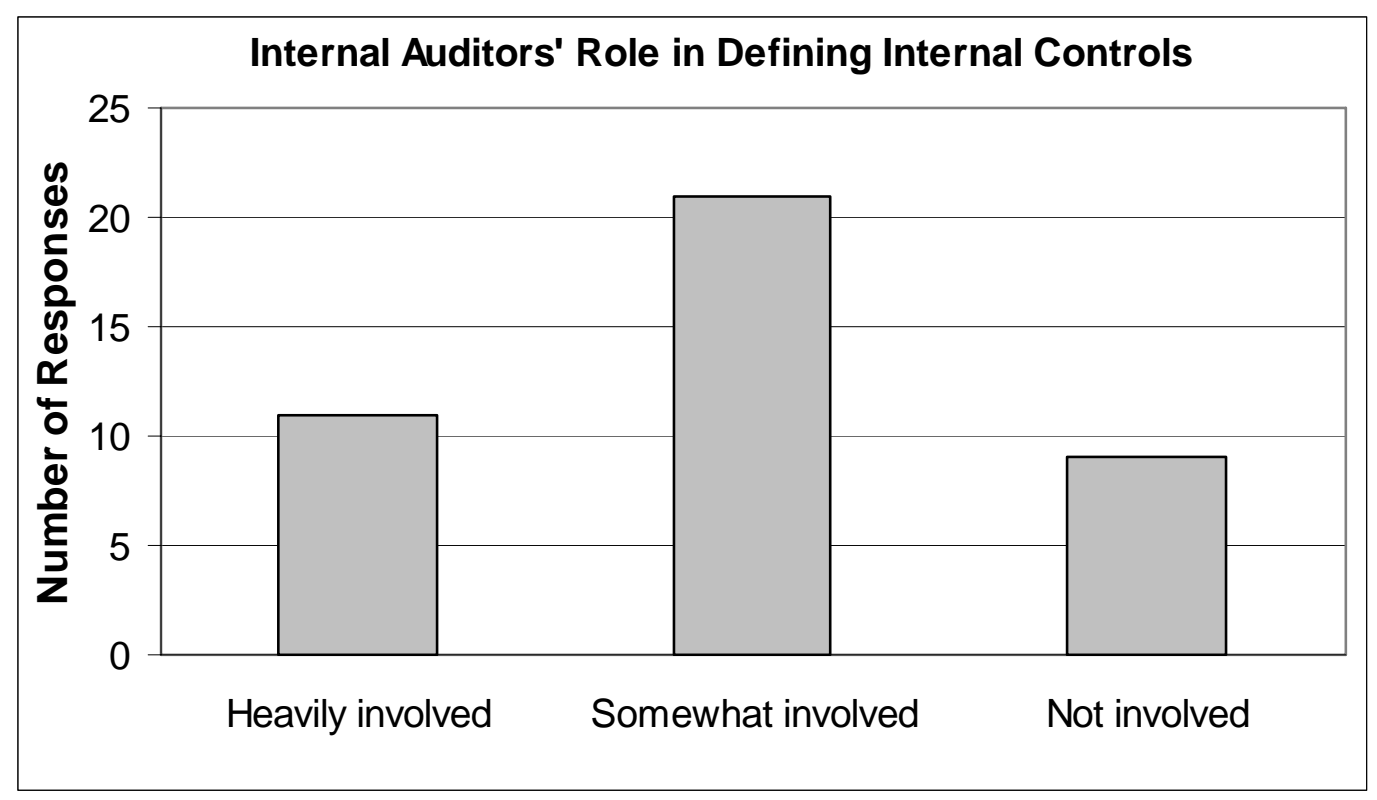

Figure 1. Role of internal auditors in defining internal controls during ERP system implementations.

\section{THE IMPACT OF ERP SYSTEMS ON RISK}

Once the ERP system implementation is complete, the organization does not have to deal with the project risks. During the operational stage, the focus becomes identifying and managing ongoing risks. In the next part of the survey, we asked the respondents to identify the whether the ERP system led to changes in the level of ongoing risks and, and irrespective whether the risk level changes or not, how it has affected their ability to assess and manage these risks. We grouped risk factors into four categories: Operational, Financial, Technological and Miscellaneous (see Table 1).

In the operations risks category, we include factors relating to physical processes (e.g., disruption in production cycles, procurement, human resources, quality assurance), external business environment (e.g., change in competitive landscape), and customer relationship management. Our survey indicates that ERP systems reduced the level for risk for most factors. The only exception is risk associated with the user training that saw a slight increase. ERP systems lead to improvement in internal auditors' capabilities for risk assessment in all categories including user training, with the biggest improvement in assessing HR and procurement related risks.

In the financial risk category, we include liquidity and credit risk, and price risk (arising because of exposures from such sources as interest rates, currency, stock prices, and commodity prices.). ERP systems seem to reduce financial risks while improving an internal auditor's ability to assess and manage these risks. Specifically, liquidity and credit risks decreased, or at the worst, stayed the same for all firms. Only two respondents indicated increase in the price risk. ERP systems led to improvement in internal auditors' ability to assess and manage these risks, with the largest improvement for the price risk.

In the technical risk category, we included factors associated with adoption of information technology, network, and data center operations, quality in data and application, availability of technical skills. Despite their ability to provide an integrated application platform, thereby eliminating many unnecessary data entry steps and awkward interfaces, surprisingly, ERP systems were perceived to increase technology risk. The biggest increases were noticed in maintenance (modifications, upgrades, and 
migrations to new systems) and personnel issues. However, the ERP system also perceived to provide better tools to assess and manage technology related risks. For all risk factors, more respondents felt that ERP systems improved their risk management ability than those that did not.

In the miscellaneous risk category, we include factors associated with fraud and reporting errors, compliance with regulatory requirements, political and legal, privacy violations. ERP systems seem to make a significant reduction in risk associated with fraud, regulatory noncompliance, and financial reporting errors. In addition to risk reduction, our survey also seems to indicate a significant improvement in the organization's ability to assess and manage the risk associated with these factors. Similar to this observation, the results indicated that ERP adoption leads to reduced risks of privacy violation and provides a better mechanism for assessing and managing this risk. ERP systems seem to have minimal effects on risks associated with legal, political, environmental, and international issues.

\section{Table 1. Risk Categorization}

\begin{tabular}{|c|c|c|c|}
\hline $\begin{array}{l}\text { Operation } \\
\text { Risks }\end{array}$ & \begin{tabular}{|l} 
Financial \\
Risks
\end{tabular} & $\begin{array}{l}\text { Technological } \\
\text { Risks }\end{array}$ & $\begin{array}{l}\text { Miscellaneous } \\
\text { Risks }\end{array}$ \\
\hline \begin{tabular}{|l|} 
a. Product Risk \\
(competition and change \\
in consumer preferences
\end{tabular} & $\begin{array}{l}\text { a. Price (interest rate, } \\
\text { currency, stock price, } \\
\text { commodity, etc.) }\end{array}$ & $\begin{array}{l}\text { a. Security (physical and } \\
\text { logical) }\end{array}$ & Political \\
\hline $\begin{array}{l}\text { b. Customer Relationship } \\
\text { (order taking, order } \\
\text { fulfillment, satisfaction) }\end{array}$ & b. Liquidity & $\begin{array}{l}\text { b. Integrity of data and } \\
\text { programs }\end{array}$ & b. Legal \\
\hline \begin{tabular}{|l|} 
c. Production \\
(interruption, cycle time, \\
health and safety)
\end{tabular} & c. Credit & $\begin{array}{l}\text { c. Network and hardware } \\
\text { availability (system } \\
\text { failure, backup, capacity } \\
\text { and salability, access, } \\
\text { etc.) }\end{array}$ & c. International \\
\hline $\begin{array}{l}\text { d. Procurement and } \\
\text { Sourcing }\end{array}$ & & d. System Support & d. Environmental \\
\hline $\begin{array}{l}\text { e. Human Resources } \\
\text { (e.g., personnel, payroll, } \\
\text { benefits) }\end{array}$ & & $\begin{array}{l}\text { e. Personnel issues } \\
\text { (turnover, expertise, } \\
\text { training, outsourcing } \\
\text { support) }\end{array}$ & $\begin{array}{l}\text { e. Regulatory other than } \\
\text { environmental }\end{array}$ \\
\hline f. User Training & & $\begin{array}{l}\text { f. System interface with } \\
\text { other systems }\end{array}$ & f. Fraud \\
\hline \multirow[t]{2}{*}{ g. Quality Assurance } & & $\begin{array}{l}\text { g. Maintenance } \\
\text { (Modification, upgrade, } \\
\text { and migration) of systems }\end{array}$ & $\begin{array}{l}\text { g. Financial reporting } \\
\text { errors or disclosures }\end{array}$ \\
\hline & & & $\begin{array}{l}\text { h. Privacy violation } \\
\text { (employee, customer, or } \\
\text { supplier) }\end{array}$ \\
\hline
\end{tabular}



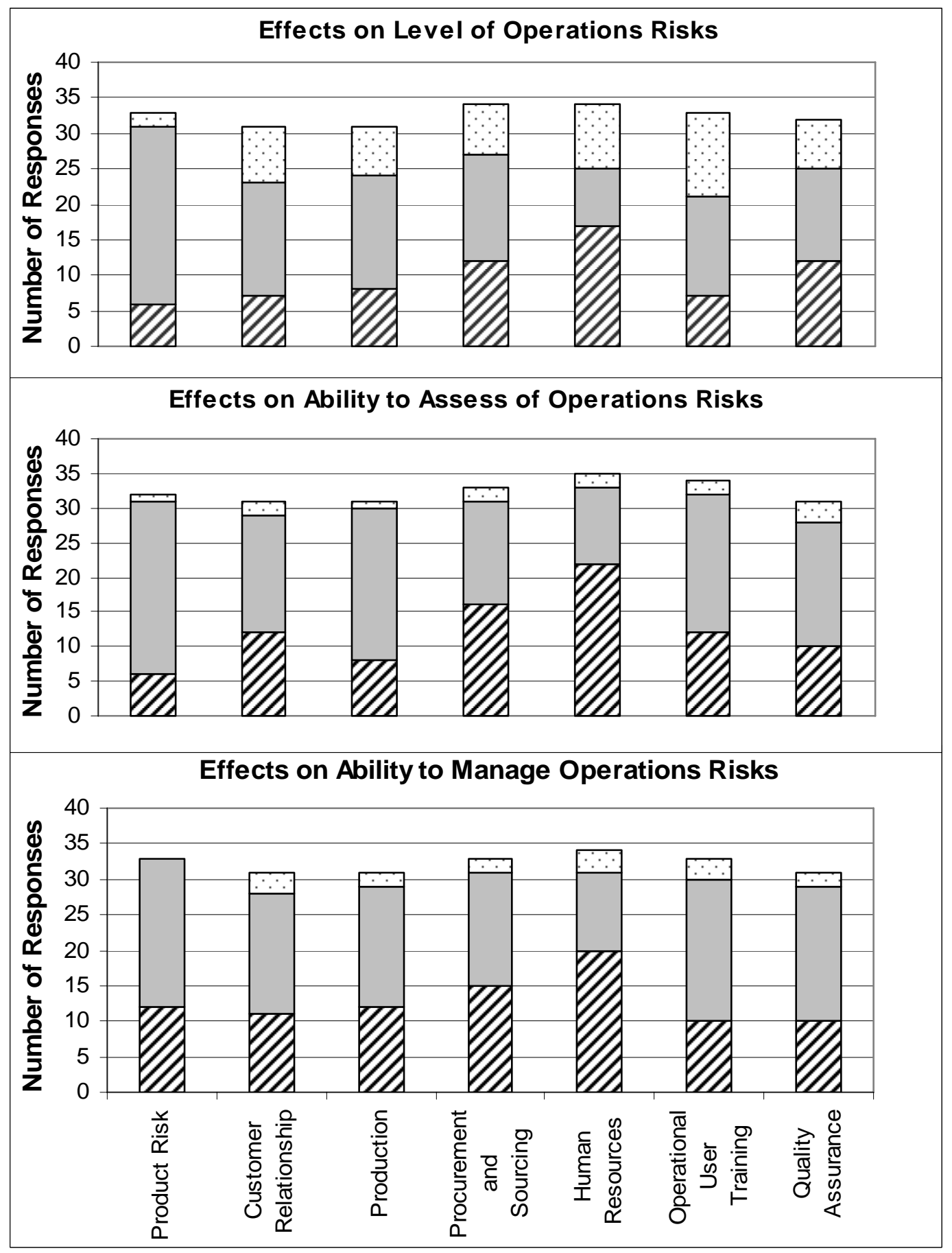

Figure 3. Effects of ERP system adoption on operational risks. About as many respondents thought that the levels for operational risks have increased as the ones that thought the levels have decreased. However, the ability of auditors to assess and manage these risks has improved.

Negative impact (increased risk level; worsened ability to asses the risk assess, worsened ability to manage the risk)

No change

Positive impact (increased risk level; worsened ability to asses the risk assess, worsened ability to manage the risk) 


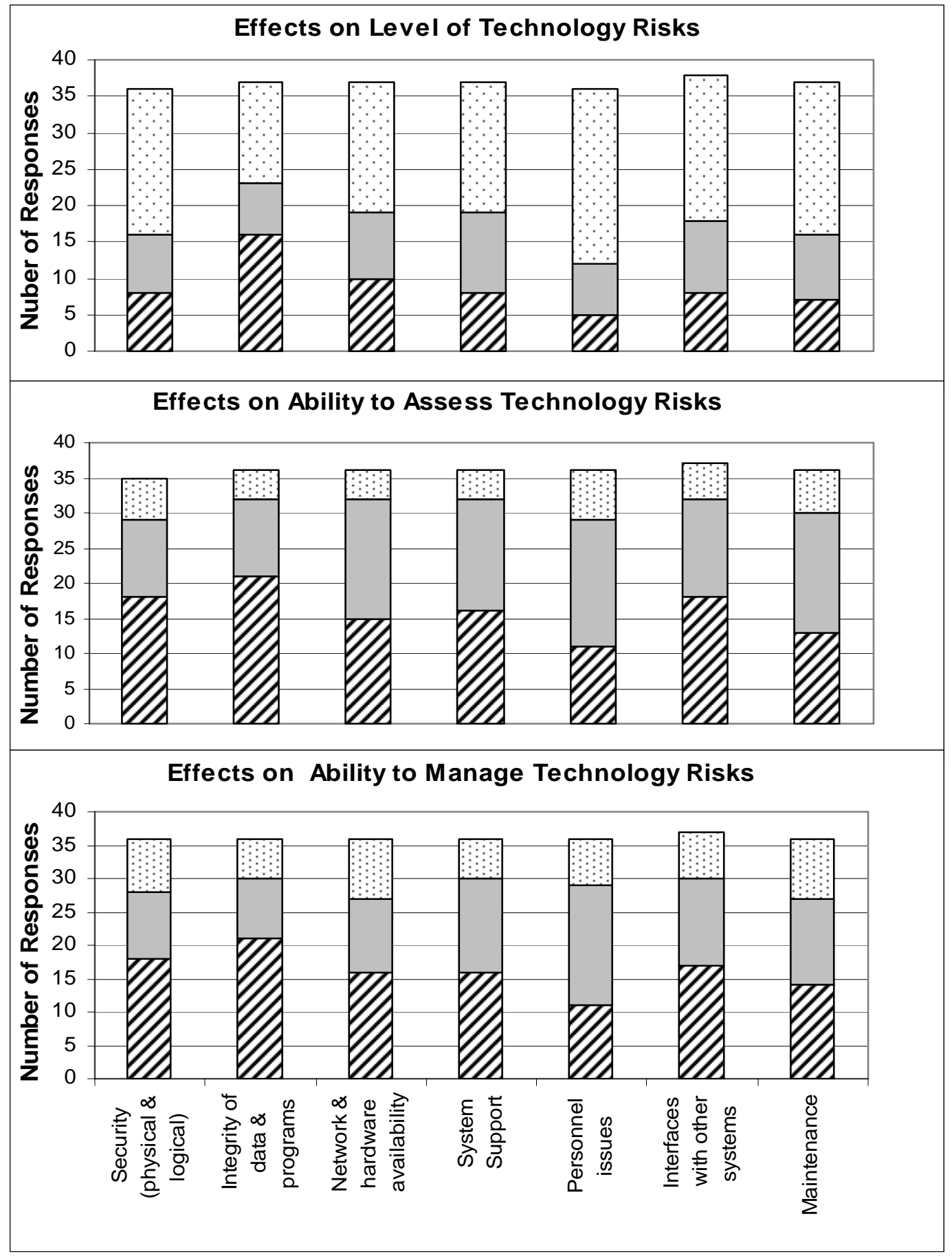

Figure 3. Effects of ERP system adoption on technology risks. For most risks in this category, the levels of the risks have increased. However, the ability of auditors to assess and manage these risks has improved.

Negative impact (increased risk level; worsened ability to asses the risk assess, worsened ability to manage the risk)

No change

Positive impact (increased risk level; worsened ability to asses the risk assess, worsened ability to manage the risk) 


\section{COST OF MANAGING RISKS}

While there is no consistent pattern over all it does seem that the cost associated with managing operations and financial risks goes down while the cost associated with managing technology risks goes up. It would be interesting to see if the pattern holds as the ERP systems become more mature and skill sets available for maintaining and managing skill become commonplace

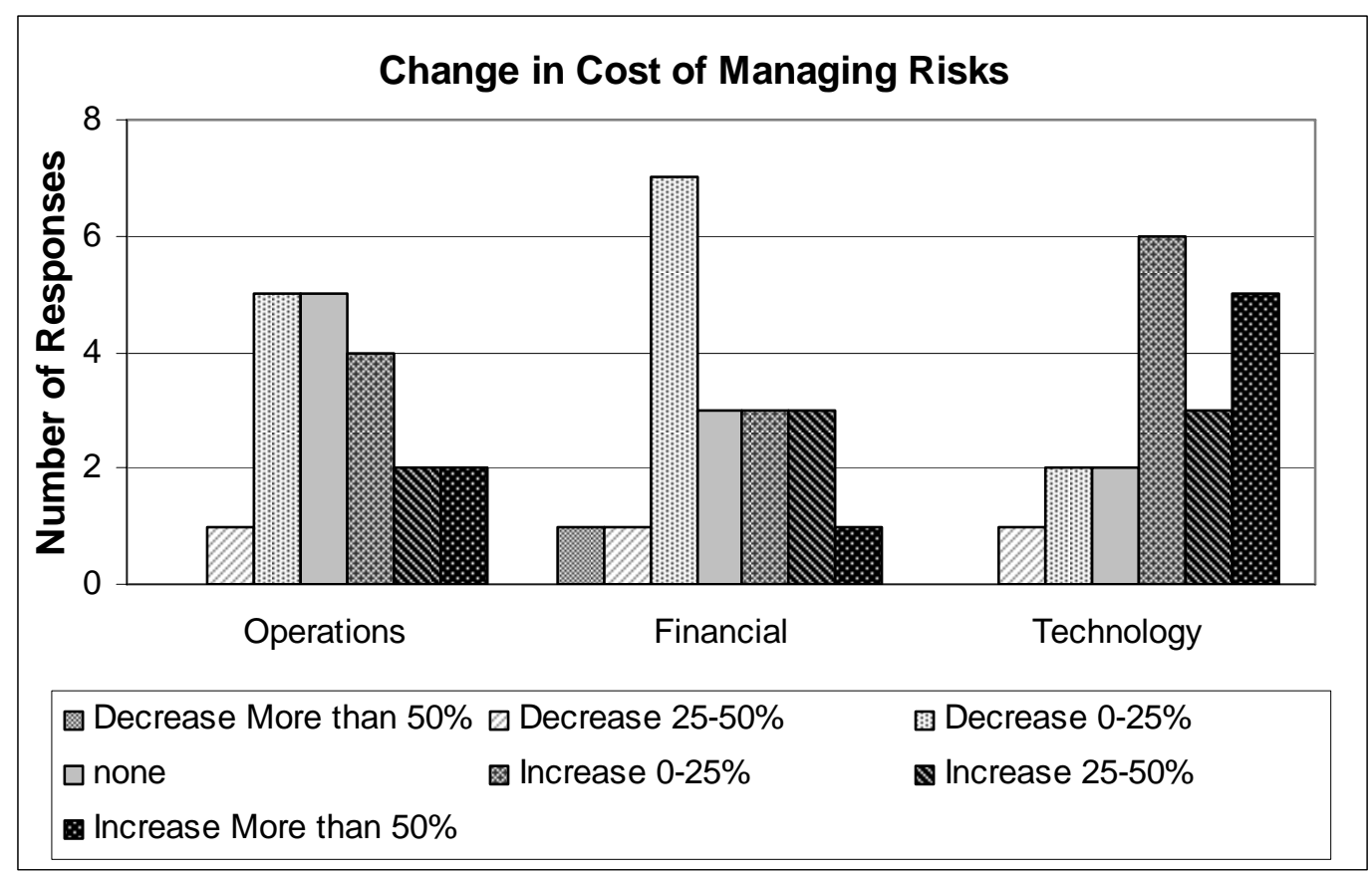

Figure 2. Effects of ERP system adoption on cost of managing risks. The costs for managing operational and financial risk has not changed significantly but the costs of managing the technology risk has gone up.

\section{INTERNAL AUDIT STAFFING AND PERSONNEL ISSUES}

ERP systems have led a significant shift in the overall focus in the internal audit function. An integrated environment leads to elimination of many points of failure by eliminating manual work and document flows. In an ERP environment, internal auditors should then spend less time in crisis management and resolving problems once they have arisen and more on making sure that the internal controls are functioning properly. As we mentioned earlier, internal auditor in our sample were not as heavily involved during the implementation stage yet most seem to think that ERP systems allow them to spend less time on managing problems and much more time on process review and quality assurance. Only two respondents indicated that quality assurance and process review receive somewhat less emphasis after ERP adoption.

Adoption of ERP system also creates a need for additional skills in the internal audit groups. In the new environment, internal auditors have to have enough knowledge and skills to understand of the internal workings of the ERP system adopted by the organization. We asked our respondents to identify how these additional skills being acquired. The responses were widely dispersed. Although some firms were willing to engage outside consultants or hire new employees, most firms chose to acquire these skills through training and reskilling current employees. Most companies view the ERP system as 
a long-term commitment, are willing to invest in employees who they believed would stay with the company. Independent study, classroom instruction, and seminars were the primary means of staying current on ERP systems.

Internal audit groups experienced only a small shift towards higher turnover after ERP implementation.
Given the increasing demand for ERP related skills, we had expected a more pronounced shift. Of course, employers may have been responsive in countering higher wages offered in the market. Alternatively, internal auditors may have seen greater job stability in being involved early in a complicated new system's implementation and traded job stability off against the possibility of higher wages in the market.

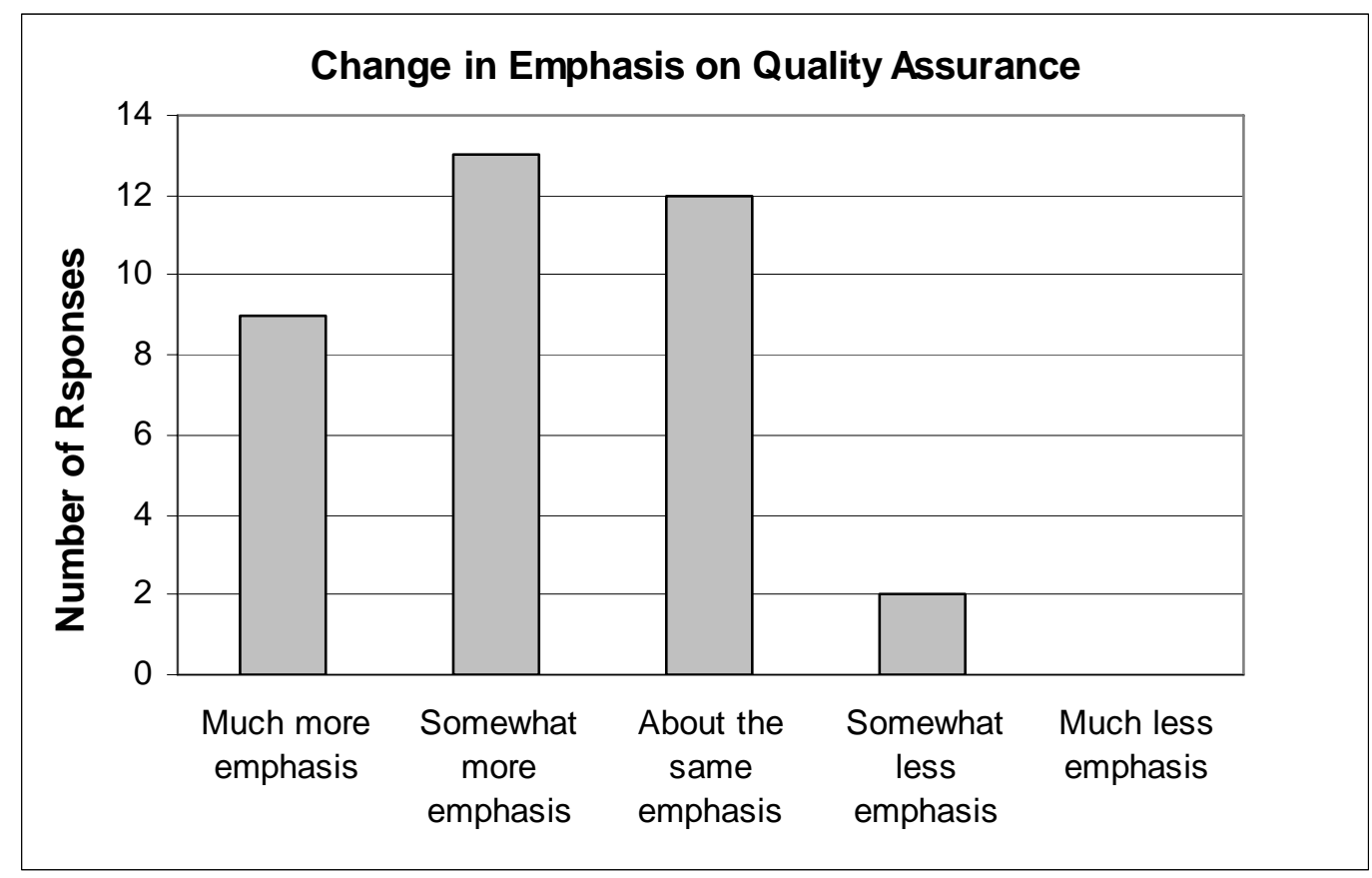

Figure 5. ERP systems adoption leads to a change in emphasis from problem solving to more process modeling and quality assurance.

Most respondents also indicated that the implementation resulted in more interaction with the CIO. This result is not surprising as internal auditors' most relevant source of knowledge of their company's ERP system would likely be the CIO or the CIO's staff. Alternatively, this increase in interaction could have been driven by job requirements that put internal auditors together with the CIO in planning meetings. The internal auditor's responsibility for insuring that certain control modules are set up properly and the need to continually test these functions could also have led to more interaction with the CIO.

\section{CONCLUSIONS, LIMITATIONS, AND FUTURE RESEARCH}

ERP systems adoption leads to a significant change in the information processing environment at the organization. The transition from fragmented ad hoc systems to integrated systems allows for automated and document flows, eliminate replications and the resulting inconsistencies in the data. They allow for built in controls to data verification and data integrity. Yet these systems are complex and require significant effort in implementing and specialized skills in customizing in maintaining the systems. ERP adoption thus lead to new risks during both during implementation and operational stages. Thus ERP 
systems have the potential to change the way risk management function in the organization. In this work, we conducted a survey of internal auditor to identify the impact that these systems are having on the audit function.

Based on our survey responses, we can infer that on one hand, ERP systems lead to a significant improvement in internal auditors' ability to assess and manage risk in most risk categories. On the other hand, we see an increases levels for in technology risk factors and operational risk factors, a decrease in financial risks, and wider variation in miscellaneous risk factors. The survey also indicates that internal auditors are spending more time in quality assurance in processes rather and less time in managing crises. However, we were surprised that internal auditors did not play a more important role in implementation, particularly in defining internal control or being part of the reengineering effort necessitated by ERP adoption.

This study is subject to limitations common to survey research design. In the early post-Sarbanes-Oxley period, volunteers responded to mostly objective questions which might not elicit the full range of their perspectives, perspectives which we assume mirror reality Our research raises many questions for future research. Our study captures internal auditors' perspectives but raises the questions why they hold those perspectives or how they came to hold them. Why were most of the implementations internally focused with so few integrated with suppliers and customers? What drove the choice of ERP vendors and did this choice relate to company or industry characteristics? Why were internal auditors generally only "somewhat involved" in the design and implementation of new internal controls into the system? If the organization or its culture changed, was that change the cause of, the result of, or was it independent of the ERP implementation? To what extent were the perceptions of risk affected not just by the implementation but also by such organizational or cultural changes? Finally, Sarbanes Oxley has and continues to dramatically affect publicly listed companies' scrutiny of internal controls. Whether this has added impetus for full integration of all ERP modules, company-wide and how internal auditors are affected by these changes warrants research on an on-going basis.

\section{REFERENCES}

1. Aloini, D., Dulmin, R., \& Mininno, V. (2007). Risk management in ERP project introduction: review of the literature. Information and Management, 44, 547-567.

2. Bae, B. \& Ashcroft, P. (2004). Implementation of ERP Systems: Accounting and auditing implications. CWU working paper. Available: http://www.cwu.edu/ baeb/ERP\%20Implementa tion\%20\&\%20Implications.doc.pdf

3. Davenport, T. 1998. Putting the enterprise into the enterprise system. Harvard Business Review 76 (4), 121-131.

4. Debreceny, R. S., Gray, G. L., Ng, J. J., Lee, K. S., \& Yau., W. (2005). Embedded audit modules in enterprise resource planning systems: implementation and functionality. Journal of Information Systems, 19 (2), 7-27.

5. Esteves, J., Pastor, J., \& Casanovas. J. (2002). Monitoring business process redesign in ERP implementation projects. Proceedings of the Eighth Americas Conferences on Information Systems, Dallas, TX USA.

6. Glover S., Prawitt, D. F., \& Romney, M. (1999) Implementing ERP. The Internal Auditor, 56 (1), 40-47.

7. ISACA Document\# G21. IS auditing guideline: Enterprise Resource Planning (ERP) systems review document. Available: http://www.isaca.org/ContentManagement/Conte ntDisplay.cfm?ContentID=34629

8. Mabert, V. A., Soni, A. K. \& Venkataramanan, M. A. (2006). Model based interpretation of survey data: a case study of enterprise resource planning implementations. Computers and Mathematical Modeling, 44 (1-2), 16-29.

9. Musaji, Y.F. (2002) Integrated Auditing of ERP Systems, New York, NY: Wiley.

10. O’Leary, D. (2004). Enterprise resource planning (ERP) systems: an empirical analysis of benefits. Journal of Emerging Technologies in Accounting, 1, 63-72.

11. Raghupathi, W., \& Saharia, A. N. (2007). Identifying risks in ERP system implementationws. Proceeding of the DSI Annual Meeting, Phoenix, AZ USA.

12. Scott, J. E., \& Vessey, I. (2002). Managing risks in enterprise systems implementations. Communications of the ACM, 45(4), 74-81. 